\title{
Arte rupestre, tiempo y espacio en La Damiana (Quebrada de Incahuasi, Salta, Argentina)
}

\section{Eugenia De Feo*}

\section{Resumen}

En este artículo se presentan los resultados del análisis espacial de las manifestaciones rupestres de La Damiana (Quebrada de Incahuasi, Salta). El conjunto estudiado abarca 163 bloques grabados que componen el Tramo 1. A partir de su análisis se busca definir cambios y continuidades en los paisajes pastoriles desde el período Formativo (700 a.C. - 1000 d.C.) al Tardío (1000 - 1430 d.C.). Interesa conocer de qué manera las representaciones tardías se organizaron espacialmente y con respecto a otras preexistentes y cómo los grabados más tempranos participaron en el marco de las estrategias de configuración de los paisajes pastoriles posteriores. Se parte de un enfoque metodológico apoyado por el empleo de herramientas SIG y que indaga acerca de la estructura espacial del arte rupestre de cada periodo en una escala de bloque, abordando aspectos distribucionales y visuales de cada subconjunto, y otra intrabloque, que considera los soportes reutilizados, los motivos en estos plasmados y sus relaciones espaciales. Se observa una recurrencia en los espacios ocupados y la forma en que han sido intervenidos a partir del arte rupestre, aunque con una mayor intensidad durante el Tardío. A la vez que surgen nuevos temas y formas de representación, se sugiere la vigencia de otros preexistentes.

\section{Rock art, time and space in La Damiana (Quebrada de Incahuasi, Salta, Argentina)}

\begin{abstract}
In this paper, we present the results of a spatial analysis of rock art from La Damiana (Quebrada de Incahuasi, Salta). We studied 163 engraved blocks, part of the Section 1 of the site, in order to define changes and continuities in the pastoralist landscapes from the Formative (700 B.C. - A.D. 1000) to the Late period (A.D. 1000 - 1430). We were interested in defining how later representations were spatially organized in relation to preexisting ones, and how the earlier engravings participated in the spatial arrangements of later pastoralist landscapes. The methodological approach supported
\end{abstract}

Recibido: 25 julio de 2017

Aceptado:

10 de enero de 2018

\section{Palabras clave}

Arte rupestre

Paisaje

Cronología

SIG

\section{Keywords}

Rock art Landscape Chronology GIS 
by the use of GIS tools, sought to define the rock art's spatial structure during each period and at different scales: a "block" scale that considered distributional and visual aspects for each chronological subset, and an "intra-block" scale that focused on reused surfaces, representations, and their spatial relationships. We observed a recurrence in the occupation of spaces and in the form in which they had been modified through rock art, with greater intensity during the Late period. Moreover, we suggest that at this moment new themes and modes of representation arose, even while some preexisting ones were still in use.

\section{Introducción}

La localidad arqueológica La Damiana (Quebrada de Incahuasi, occidente de la provincia de Salta) se encuentra ubicada sobre la ladera noreste del Nevado de Acay, en un amplio cono de deyección surcado por cursos de agua y caracterizado por la presencia de varios humedales (Figura 1). Este sector es mencionado por primera vez en la bibliografía arqueológica por Boman (1908), quien cita la presencia de bloques de piedras grabadas con motivos abstractos. Años más tarde, Fadel (1977) señala la existencia de grabados en el área, a la que denomina Campo de los petroglifos. Raffino realiza excavaciones en el sitio Pie del Acay y, si bien no hace referencia al arte rupestre, publica varios bloques grabados ubicados en las inmediaciones del sitio Santa Rosa de Tastil en el Abra de Romero (Raffino, 1977), a unos $15 \mathrm{~km}$ al sur de La Damiana, cuyo estudio es retomado años más tarde por Meninato (2008). En el año 2007 damos a conocer los resultados de las primeras prospecciones en la quebrada de Incahuasi, publicación que es seguida de una serie de trabajos y presentaciones (De Feo, 2013, 2014a y b, 2015; De Feo y Ferrauiolo, 2007) donde caracterizamos los motivos y temáticas del arte rupestre local, su emplazamiento en el terreno y posible cronología - basada en criterios estilísticos y en la pátina observada-, a la vez que ofrecemos interpretaciones sobre su funcionalidad, que vinculamos principalmente al pastoreo de camélidos. En esta oportunidad se indaga acerca de la estructura espacial del arte rupestre local, en momentos formativos hasta el período Tardío, como una forma de aproximarnos al estudio de los paisajes pastoriles en el contexto de los procesos de cambios sociopolíticos ocurridos a partir del 1000 de la era cristiana en la región.

Los bloques con arte rupestre de La Damiana, que en la actualidad ascienden a un total relevado de 672, se disponen en forma paralela a cursos de agua, tanto actuales como paleocauces, demarcando vegas o, en ocasiones, próximos a espacios de vivienda o productivos.

También se localizan diversas estructuras que incluyen recintos de vivienda, sectores productivos agrícolas, corrales, senderos, alineamientos de piedra, estructuras monticulares de tierra, apachetas y las llamadas "trampas de zorro". La evidencia señala una extensa profundidad temporal para la ocupación del área, la cual se remonta al Período Formativo (700 a.C. - 1000 d.C.) según se ha documentado a la fecha. Así lo indica la presencia de estilos alfareros Vaquerías y San Francisco, tanto en superficie como en excavación, en los sitios Pedro Cruz y Muro Ancho, donde se registran algunas estructuras circulares aisladas (De Feo, 2017), como también los motivos y temáticas plasmadas en el arte rupestre sobre los que volveremos más adelante. Como ya hemos mencionado, la ocupación del área durante el período Tardío fue informada anteriormente por Raffino (1972), a raíz de sus excavaciones en Pie del Acay. Este asentamiento, al que define como un sitio de producción agrícola tardío, está conformado por cuadros de cultivo de forma rectangular, acequias y escasos recintos de vivienda. Prospecciones realizadas en el área recientemente nos han permitido 


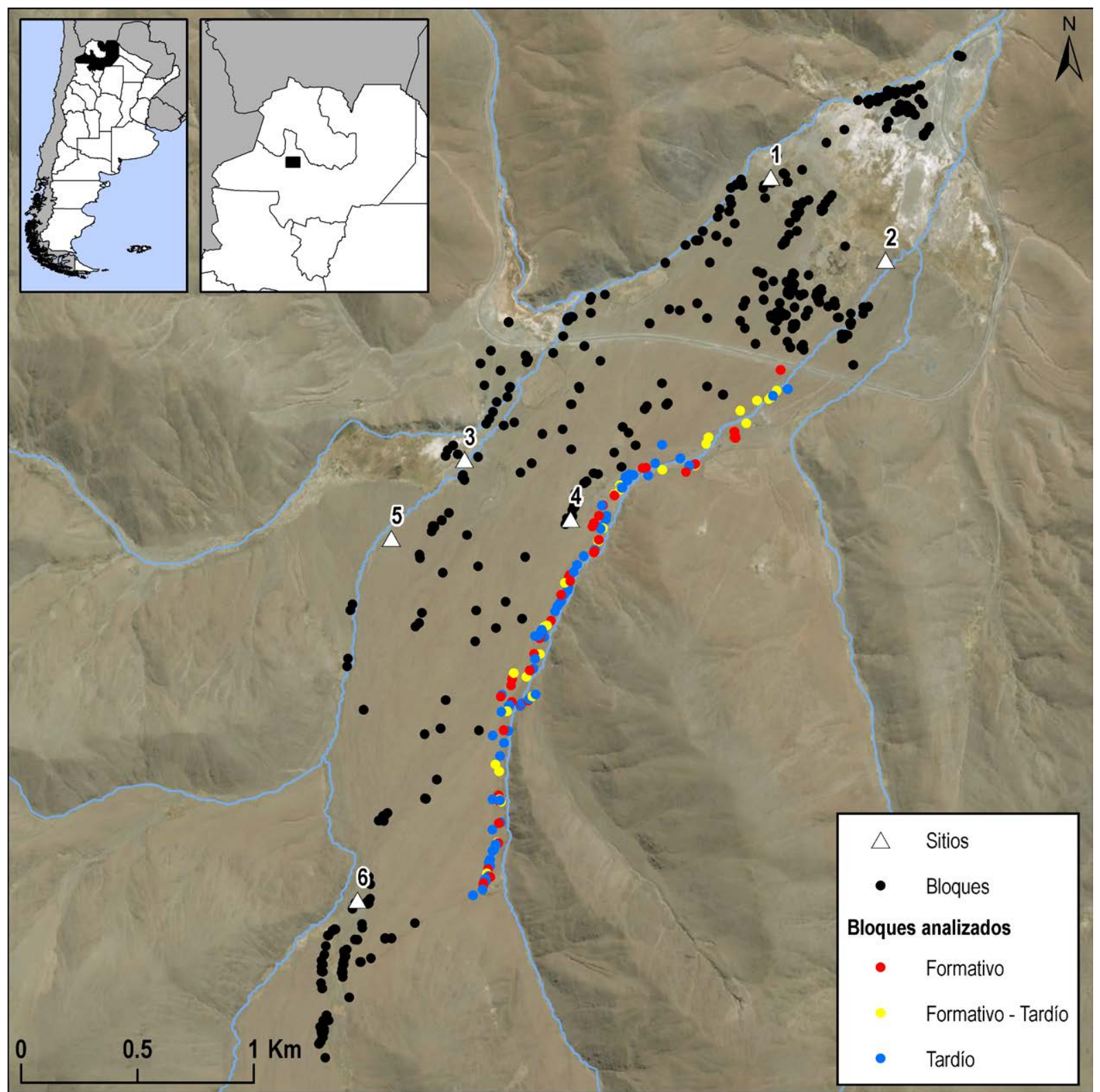

Figura 1. Área de estudio con ubicación del conjunto total de bloques grabados documentados en La Damiana. En color se indican los que integran el Tramo 1 y su cronología. Sitios asociados que se mencionan en el texto: 1) Cahez; 2) Muro Ancho; 3) Pedro Cruz; 4) Corral del Acay; 5) Pie del Acay; 6) Molino Viejo.

localizar otros sectores con estructuras (Molino Viejo, Cahez, Corral del Acay, entre otros), también compuestos por grandes recintos cuadrangulares, posiblemente cuadros de cultivo o canchones, o por agrupamientos de varios recintos de menores dimensiones, que pensamos pueden ser espacios de residencia por su similitud con otros sitios conocidos (Raffino, 1972), ambos con cerámica en superficie asignable a estilos propios de momentos tardíos (De Feo, 2017). Se observa asimismo un mayor número de estructuras arquitectónicas con estas características de construcción, en comparación con las evidencias de asentamiento y uso del espacio más tempranas, aspecto que daría cuenta de una intensificación en la ocupación efectiva del área. En la actualidad, si bien la agricultura ha sido prácticamente abandonada o se limita a reducidos huertos familiares a causa de la escasez de agua para el riego, la ocupación humana continúa vinculada al pastoreo del ganado caprino y ovino. Las manifestaciones 
de arte rupestre más modernas surgen en el contexto de esta última actividad y otra parte importante está relacionada con los ascensos de montañistas al Nevado de Acay.

Partiendo de la idea de que el arte rupestre actúa como un dispositivo material que crea, organiza y semantiza el paisaje, a la vez que produce estrategias de movimiento en el espacio (Troncoso, 2007), hemos propuesto que los conjuntos de La Damiana han tenido un rol en la demarcación de territorios y rutas en el marco de circuitos de movilidad y aprovechamiento de recursos vinculados al manejo de camélidos durante momentos prehispánicos (De Feo, 2015; De Feo y Ferrauiolo, 2007). Esta interpretación se desprende de las características ecológicas donde se ubica este arte rupestre, esto es, sectores con alta concentración de recursos forrajeros y además transicionales, en tanto conectan ecosistemas contrastantes mediante pasos naturales, así como la disposición de los bloques delineando senderos. Esto también puede sostenerse considerando los motivos y las temáticas como por ejemplo la alta representación de figuras de camélidos con cánones que indican - aunque no siempre- animales domésticos, alineaciones de camélidos, camélidos circunscriptos por líneas a modo de corrales o senderos y camélidos vinculados a figuras humanas o mascariformes yuxtapuestos. También están presentes, aunque en menor proporción, motivos asociados al caravaneo de camélidos en el área Centro Sur Andina, por lo que no podemos descartar su participación en esta actividad. Entre ellos se registran personajes guía (antropomorfos con bastones o brazos alzados), camélidos unidos por sogas, camélidos con tarabitas, círculos concéntricos con o sin apéndices, espirales y círculos con punto interior (Aschero, 2000; Martel, 2011; Núñez, 1985).

Entonces, consideramos al arte rupestre como un elemento clave en la reproducción de las comunidades prehispánicas locales y la significación de lugares, en especial - aunque no de forma excluyente-, de aquellos paisajes vinculados al ámbito productivo pastoril. Asimismo, este arte grabado en la piedra es caracterizable como un elemento perdurable (Armstrong, 2012) y visible en el paisaje (monumental en el sentido de Criado, 1993, p. 47) que, como ya hemos mencionado para este caso, evidencia una extensa secuencia de ocupación del área. Debido a esta condición, los grabados también estuvieron presentes y fueron consumidos por poblaciones que habitaron o hicieron uso de ese espacio con posterioridad a quienes los crearon. Sin embargo, desconocemos de qué manera estas manifestaciones preexistentes fueron incorporadas en nuevas o sucesivas estrategias de configuración del paisaje. Diversos estudios han abordado este tema desde un enfoque orientado a definir el rol del arte rupestre en la memoria colectiva de las sociedades prehispánicas (Armstrong, 2012; Martel, Rodríguez Curletto y Del Bel, 2012), así como en procesos de cambio socioeconómicos y simbólicos (Martel, 2009; Martel y Aschero, 2007). Sabemos que en la Quebrada del Toro, de la cual es afluente Incahuasi, el período Tardío se caracterizó por cambios sociopolíticos que dieron lugar al surgimiento de importantes centros poblacionales y administrativos, como es el caso de Santa Rosa de Tastil, y la presencia de sitios con variadas modalidades de asentamiento (Soria, 2007). Esto estuvo acompañado por una intensificación de la explotación agrícola, documentada por la presencia de sitios especializados en esta actividad (Cigliano y Raffino, 1973; Raffino, 1972). Asimismo, se cuenta con evidencia, de que el pastoreo de camélidos tuvo una importante incidencia en la economía de estas poblaciones, hecho que también se ha constatado en comunidades formativas (De Feo, 2015; Raffino, 1977). Así lo testimonia el arte rupestre registrado en la zona (De Feo y Ferrauiolo, 2007; Meninato, 2008; Raffino, 1967) y los restos de arqueofauna recuperados en áreas de residencia y basurales (Raffino, Tonni y Cione, 1977). Partiendo de esta información, nos interesa establecer cambios y continuidades en los paisajes vinculados al pastoralismo, como vía para aproximarnos a las prácticas y las relaciones sociales en las cuales surgieron tales configuraciones espaciales (Gregory, 1978), entendiendo además, que este arte rupestre está relacionado con determinados conceptos y estrategias que son propias 
de cada sistema de saber-poder (Troncoso, 2005). A fin de comprender estos procesos desde una perspectiva temporal amplia, en un recorte que comprenderá el Período Formativo y Tardío, el objetivo de este trabajo será conocer la estructura espacial del arte rupestre en diferentes momentos de la ocupación del área y evaluar, además, si las manifestaciones más tempranas fueron excluidas o incluidas en los paisajes tardíos. De constatarse esto último, nos interesa conocer de qué manera las manifestaciones previas participaron en estas nuevas configuraciones. Establecer esto nos permitirá acercarnos no sólo a la manera en que las poblaciones que vivieron en el área se relacionaron con el pasado sino también delinear persistencias y cambios en los contextos pastoriles a lo largo del tiempo.

\section{Materiales y métodos}

Basándonos en la disposición lineal y en la distribución con continuidad en el espacio de los bloques grabados, hemos segmentado el conjunto en diferentes tramos para su relevamiento y estudio. El Tramo 1 es el más estudiado a la fecha y sobre el mismo se concentrarán los análisis que aquí presentamos (Figura 1). Este tramo está conformado por un total de 252 bloques con grabados, dispuestos de forma paralela a un curso de agua permanente denominado localmente "el chico", que desciende del Nevado de Acay bordeando la ladera del cerro. La gran mayoría de bloques se ubica sobre la margen izquierda del cauce y sólo algunos pocos lo hacen sobre la derecha, en el área baja del abanico aluvial o en zonas muy escarpadas pendiente arriba. Se presentan emplazados en el perfil de la barranca o por encima de esta, a una distancia media de $35 \mathrm{~m}$, nunca superando los $135 \mathrm{~m}$ al cauce de agua.

Los soportes utilizados son basaltos y esquistos dispersos naturalmente en el área, que han sido grabados mediante la técnica de picado continuo o discontinuo en figuras de cuerpo lleno o de surco picado continuo y, en menor medida, el raspado o el grafiti en los más modernos.

La cronología del arte rupestre se estableció de forma relativa basada en un criterio estilístico, aunque la técnica utilizada, la presencia de superposiciones y la pátina observada fueron variables también consideradas. Se tomaron de referencia motivos diagnósticos de la cronología establecida en secuencias propuestas para otras regiones del Noroeste Argentino (NOA) (Aschero, 2000; Aschero y Korstanje, 1996; Aschero, Podestá y García, 1991; Fernández, 1988-1989; Fernández Distel, 1998; Lanza, 1996; Martel, 2011; Meninato, 2008; Muscio, 2006; Olivera y Podestá, 1993; Podestá, 1986-1987), así como también representaciones realizadas en otros soportes (alfarería, textiles, entre otros).

Las representaciones figurativas son más abundantes que las abstractas, predominando los camélidos en el conjunto general. En la Tabla 1 se mencionan los motivos identificados en el Tramo 1, así como su posible asignación cronológica.

Los estudios realizados previamente se enfocaron en aspectos cronológicos y formales de los motivos y de las temáticas plasmadas, así como en las condiciones de emplazamiento a una escala de sitio (De Feo, 2015; De Feo y Ferrauiolo, 2007). El enfoque metodológico que se presenta se centrará en el análisis de los diferentes bloques, de su estructuración y relaciones espaciales. Con esto se busca caracterizar cuál fue la intensidad del arte rupestre en el área en cada momento, conocer su distribución en el paisaje y establecer relaciones espaciales y visuales entre bloques y motivos con igual o distinta cronología.

Todo lo anterior implicó un trabajo intensivo de relevamiento en el campo, donde se georreferenció con GPS (geoposicionador satelital) cada bloque localizado y se relevaron los atributos estilísticos y tecnológicos del arte rupestre, además de variables 


\begin{tabular}{|c|c|c|}
\hline \multicolumn{3}{|c|}{ Motivos y cronología } \\
\hline Tipos & Formativo & Tardío \\
\hline $\begin{array}{l}\text { Figuras } \\
\text { humanas }\end{array}$ & $\begin{array}{l}\text { Figura humana de contorno geométrico elongado, } \\
\text { puede presentar extremidades inferiores } \\
\text { semiflexionadas } \\
\text { Figura humana esquemática de tipo lineal, semiperfil } \\
\text { Figura humana de frente, de tratamiento lineal, con } \\
\text { detalles del rostro, tocado y orejeras, con círculos } \\
\text { concéntricos en brazos } \\
\text { Figura humana de frente o semiperfil, con contornos } \\
\text { redondeados, cabeza subtriangular } \\
\text { Figura humana zoomorfizada } \\
\text { Pisadas antropomorfas } \\
\text { Mascariforme }\end{array}$ & $\begin{array}{c}\text { Figura humana de semiperfil, con túnicas } \\
\text { subtriangulares “uncu”, con o sin tocados, pueden o no } \\
\text { portar objetos } \\
\text { Figura humana de contorno rectangular delineado, } \\
\text { de frente, con extremidades inferiores rectas, pueden } \\
\text { portar objetos, detalles del rostro y/o tocados } \\
\text { Figura humana de cuerpo lleno, de frente, de contornos } \\
\text { más o menos redondeados, con o sin tocado, con } \\
\text { indicación de movimiento } \\
\text { Figura humana de cuerpo lleno, de frente o semiperfil, } \\
\text { de contornos más o menos redondeados, con tocado, } \\
\text { portando objetos } \\
\text { Escutiforme } \\
\text { Figura humana zoomorfizada } \\
\text { Torso con brazos alzados } \\
\text { Mascariforme }\end{array}$ \\
\hline Simios & $\begin{array}{l}\text { Figura de perfil, de tratamiento lineal, con cola } \\
\text { enroscada, puede presentar objetos en sus manos }\end{array}$ & \\
\hline Camélidos & $\begin{array}{c}\text { Camélido de perfil o semiperfil, de contornos curvos, } \\
\text { con tratamiento plano, cuerpo más o menos largo, } 204 \\
\text { patas y } 2 \text { orejas } \\
\text { Camélido de semiperfil, estilizado, de patas largas } \\
\text { delgadas y aguzadas, con orejas y cola } \\
\text { Camélido bicéfalo } \\
\text { Camélido felinizado } \\
\text { Camélido de tratamiento líneal, de cuerpo ovoide con } \\
\text { dos extremidades }\end{array}$ & $\begin{array}{l}\text { Camélido esquemático, de cuerpo lineal, de perfil } \\
\text { estricto } \\
\text { Camélido de patrón geométrico o rectilíneo de } \\
\text { tratamiento plano, de perfil estricto. Con orejas hacia } \\
\text { adelante o rectas, con cola hacia adelante o hacia atrás. } \\
\text { Puede tener insinuado autopodio. Con o sin lazos. } \\
\text { Camélidos con pechera y/o enflorados }\end{array}$ \\
\hline Aves & $\begin{array}{c}\begin{array}{c}\text { Suri de perfil, de tratamiento plano, estilizado de } \\
\text { contornos redondeados, generalmente con dos } \\
\text { extremidades }\end{array} \\
\text { Suri de tratamiento lineal, de cuerpo oval con dos } \\
\text { extremidades } \\
\text { Ave acuática de patas cortas y pico exagerado } \\
\text { Tridígito }\end{array}$ & $\begin{array}{c}\text { Suri de perfil o frente, de tratamiento plano, con una } \\
\text { extremidad con tridígito, representado en movimiento } \\
\text { con alas desplegadas } \\
\text { Suri de perfil, de tratamiento plano, con una extremidad } \\
\text { con tridígito representado estático } \\
\text { Tridígito }\end{array}$ \\
\hline Felinos & $\begin{array}{c}\text { Felino en vista lateral con garras frontales, de } \\
\text { tratamiento lineal, con fauces y manchas } \\
\text { Garra felina }\end{array}$ & $\begin{array}{l}\text { Felino de tratamiento plano, de contornos más o } \\
\text { menos redondeados, de perfil, con extremidades } \\
\text { proporcionadas, rabo exagerado y enroscado }\end{array}$ \\
\hline Ofidios & $\begin{array}{l}\text { Ofidio de cuerpo lineal simple, con } 1 \text { o } 2 \text { cabezas } \\
\text { Ofidio con atributos felínicos }\end{array}$ & $\begin{array}{l}\text { Ofidio lineal de cuerpo lleno, con motivos internos, } 1 \text { o } \\
\qquad 2 \text { cabezas } \\
\text { Ofidio de cuerpos formados por rombos o triángulos }\end{array}$ \\
\hline Biomorfos & Posible saurio & Posible cánido \\
\hline Abstractos & $\begin{array}{c}\text { Puntos aislado o agrupados } \\
\text { Trazo corto "muesca" } \\
\text { Línea sinuosa abierta o cerrada } \\
\text { Círculo, círculo radiado, círculo concéntrico con radios } \\
\text { interiores "rueda", círculo unido por líneas } \\
\text { Espiral }\end{array}$ & $\begin{array}{c}\text { Puntos aislados o agrupados } \\
\text { Línea recta aislada } \\
\text { Línea sinuosa abiertas o cerrada } \\
\text { Cruz de contorno curvilíneo } \\
\text { Trazo corto "muesca" } \\
\text { Espiral } \\
\text { Círculo, círculo radiado, círculo con trazos exteriores } \\
\text { Línea y figura escalonada } \\
\text { Triángulos unidos } \\
\text { Cuadro, cuadros concéntricos, } \\
\text { cuadros cuatripartitos, cuadros abiertos } \\
\text { Greca } \\
\text { Labertintiforme }\end{array}$ \\
\hline
\end{tabular}

Tabla 1. Motivos registrados en el Tramo 1 de La Damiana y cronología. 


\begin{tabular}{|l|c|}
\hline Cronología & N bloque \\
\hline Formativo & 46 \\
Formativo - indet. & $\mathbf{1}$ \\
Formativo - Tardío & 37 \\
Tardío & 74 \\
Tardío - indet. & 5 \\
Modernos & 3 \\
Indeterminada & $\mathbf{7 8}$ \\
\hline Total & $\mathbf{2 4 4}$ \\
\hline
\end{tabular}

Tabla 2. Bloques in situ del Tramo 1 de La Damiana y su asignación cronológica.

como la ubicación, orientación de las caras grabadas, aspectos y relaciones visuales y espaciales. Esto fue seguido de un trabajo en gabinete que se apoyó metodológicamente en el empleo de Sistemas de Información Geográfica (SIG). En esta plataforma la información fue organizada en mapas de distribución asociados a bases de datos, donde se consignaron las variables consideradas en los diversos análisis: número de bloque, número y tipo de motivos, técnica de ejecución, estado de conservación, número de caras grabadas y orientación y dirección de las mismas, posición en unidades del paisaje, cronología, reutilización de soportes, tamaño del bloque, distancias y aspectos visuales.

Del total de bloques que componen el Tramo 1, unos 244 no presentaron indicios de haber sido movidos de su localización original. Dentro de ese conjunto se seleccionaron para su análisis 163 bloques asignables cronológicamente a momentos formativos y/o tardíos (Tabla 2; Figura 1).

Se emplearon dos escalas de análisis para abordar nuestro problema. La primera de ellas considera al bloque como una unidad analítica. Dado que una cualidad del arte rupestre es la de ser contemplado visualmente y que su visibilidad está condicionada y es condicionante de su ubicación - a la vez que esto pauta ciertas formas de circulación o movilidad en el espacio-, se analizaron aspectos distribucionales y visuales de los conjuntos. En este sentido, se evaluó la disposición de cada bloque y su relación con aspectos del paisaje tales como cursos de agua y otros elementos de la topografía. Además, partiendo del hecho de que el arte rupestre establece vínculos con su entorno pero también entre sí con otros bloques, se buscó definir las relaciones espaciales (distancias) y visuales (visibilidad y visualización) que se establecen entre los mismos.

En cada análisis se incorporó la cronología del arte rupestre. Con este fin, el conjunto fue segmentado previamente en dos subconjuntos temporales, uno Formativo y otro Tardío ${ }^{1}$ Y en los casos en que los bloques presentaron reutilización, estos fueron incluidos en ambos subconjuntos. La muestra quedó conformada entonces por un total de 84 bloques que poseen motivos formativos y unos 116 tardíos. Por otra parte, para la realización del análisis del número de caras grabadas y motivos por bloque, la muestra se segmentó en tres subconjuntos - bloques formativos $(n=44)$, tardíos $(n=72)$ y reutilizados $(\mathrm{n}=32)$ - a fin de separar aquellos bloques con motivos exclusivamente tempranos de aquellos que además habían sido reutilizados con posterioridad.

En primera instancia se establecieron las distancias más cercanas que separan los bloques empleando la herramienta $\mathrm{Near}^{2}$ del paquete estadístico del programa ArcGIS 10.2, a partir de las cuales se calcularon distancias mínimas, medias y máximas para cada subconjunto.
1. En este trabajo se ha organizado la evidencia según dos grandes bloques temporales debido a las limitaciones de resolución del esquema cronológico actualmente disponible: uno Formativo, que incluye las manifestaciones más tempranas, asignables al Formativo inferior (700 a.C. - 400 d.C.) y Formativo Superior $(400-1000$ d.C.) y otro Tardío (1000 - 1430 d.C.). Respecto de este último, cabe la posibilidad de que algunas representaciones correspondan a momentos inkaicos. Tal sería el caso de los camélidos de patrón lineal, aunque por el momento la ausencia de diferencias en las pátinas no ha permitido ajustar la cronología.

2. Para la realización de los cálculos de distancias los datos fueron proyectados en coordenadas Gauss Krugger. 
Estos resultados se compararon mediante la aplicación de un test de significancia, lo cual permitió establecer si existen o no diferencias estadísticas en las distancias entre bloques de cada momento. Este mismo procedimiento se utilizó para evaluar las distancias que separan cada subconjunto de bloques del curso de agua al cual se alinean.

La orientación de las caras grabadas se relevó en el terreno con brújula y se clasificó en cuatro cuadrantes: noreste (entre 0 y $90^{\circ} \mathrm{N}$ ), sudeste (entre 90 y $180^{\circ} \mathrm{N}$ ), sudoeste (entre 180 y $270^{\circ} \mathrm{N}$ ) y noroeste (entre 270 y $360^{\circ} \mathrm{N}$ ). Una quinta categoría, Cenital, incluyó los bloques cuya cara grabada es la superior horizontal. Esto permitió establecer tendencias en la orientación cardinal de las caras grabadas de cada subconjunto y testear regularidades a lo largo del tiempo. Asimismo, y dado que el Tramo 1 conecta el fondo de valle con la base del Nevado de Acay, se evaluó el sentido o dirección de desplazamiento desde donde pueden ser vistas las caras grabadas. Esto es, discurriendo en sentido hacia el Acay, desde el Acay o indistintamente en ambos sentidos. Luego se comparó la evidencia para ambos momentos buscando definir variaciones temporales en ese aspecto. Al mismo tiempo y con respecto a la ubicación desde la cual puede contemplarse el arte, se evaluó la posición del observador en las unidades de paisaje — barranca arriba, barranca abajo, ambas o desde la planicie- pensando en definir disposiciones desde las cuales los bloques grabados pudieron ser vistos, así como posibles cambios en el tiempo.

Los aspectos de la visibilidad fueron trabajados en una matriz de datos donde se consignaron qué soportes intervenidos se observan desde cada bloque (Armstrong, 2012). Se consideraron sólo aquellos donde es posible identificar motivos grabados. Esta matriz invertida permitió calcular desde qué bloques son observables otros y el número de veces en que esto ocurre, de forma tal de ponderar su visualización. Sobre la base de la información recogida en la matriz de datos se establecieron cuatro categorías de visualización: 1) no es visto desde ningún bloque; 2) es visto desde un bloque; 3) es visto desde dos bloques; 4) es visto desde más de dos bloques. Luego se testeó si existen diferencias entre ambos subconjuntos temporales para esta variable.

El tamaño de los bloques - variable fuertemente ligada a la visibilidad - también fue considerado. Para tal fin, los tamaños se midieron con cinta métrica en terreno y posteriormente se establecieron cinco rangos: muy pequeño (menor a $0,15 \mathrm{~m}^{2}$ ); pequeño (entre 0,15 y $0,30 \mathrm{~m}^{2}$ ), mediano (entre 0,30 y $0,50 \mathrm{~m}^{2}$ ), grande (entre $0,50 \mathrm{y}$ $1 \mathrm{~m}^{2}$ ) y muy grande (más de $1 \mathrm{~m}^{2}$ ).

Por último, vinculados con la intensidad de uso del espacio, se registraron y analizaron el número de caras grabadas y motivos por bloque. Sobre la última variable, se definieron cuatro categorías: 1) bloques con un motivo; 2 ) bloques con dos a diez motivos; 3 ) bloques con 11 a 20 motivos; 4) bloques con más de 20 motivos. En estos análisis la muestra se segmentó en tres subconjuntos, uno formativo, otro tardío y un tercero, que incluyó los bloques reutilizados. Esto permitió separar los bloques formativos estrictamente de aquellos con reutilización, que también presentan motivos o caras grabadas durante el periodo Tardío.

Desde una segunda escala analítica, y complementaria de la anterior, se analizaron cualitativamente los bloques reutilizados, evaluando la relación espacial entre motivos con diferente cronología en un mismo soporte y las técnicas utilizadas, con especial atención a las asociaciones recurrentes, la presencia de superposiciones y yuxtaposiciones.

\section{Resultados}

Comenzaremos con los resultados de los análisis distribucionales. Una variable considerada fue la distancia entre bloques. Los resultados que surgen de su análisis 
estadístico sugieren que no existen diferencias significativas en las distancias que separan los bloques en momentos formativos y tardíos (Tabla 3 ) ( $\mathrm{T}=0,58$; gl 198; $\mathrm{p}=0,5592)$.

Resultados similares se obtuvieron al analizar la distancia de los bloques a los cursos de agua para cada subconjunto cronológico (Tabla 3). En esta oportunidad el test de Student arrojó que tampoco existen diferencias significativas entre el conjunto de bloques formativos y tardíos respecto de las distancias que los separan de los cauces ( $\mathrm{T}=0,23 ; \mathrm{gl} 198 ; \mathrm{p}=0,8188)$.

En lo que respecta a la orientación de las caras grabadas, se observó un marcado predominio de las orientaciones sudeste y noreste, seguidas por las sudoeste y noroeste, mientras que las caras cenitales son muy escasas (Tabla 4; Figura 2). Esta tendencia se verifica tanto para el conjunto de bloques formativos, como de los tardíos. Los resultados del test de Chi Cuadrado Pearson mostraron que no existen diferencias significativas para esta variable entre los subconjuntos $\left(X^{2}=3,95 ; \mathrm{gl} 4\right.$; $\left.\mathrm{p}=0,4128\right)$.

También se mencionó que la selección de las caras grabadas determina un sentido de desplazamiento para que estas sean vistas. En la Tabla 4 se aprecia que la gran mayoría de caras grabadas son observables tanto en un sentido de desplazamiento hacia el nevado de Acay como inversamente (Figura 2), no existiendo diferencias significativas entre ambos subconjuntos $\left(\mathrm{X}^{2}=1,13 ; \mathrm{gl} 2 ; \mathrm{p}=0,5689\right)$.

La posición de observación fue otra de las variables evaluadas. Los resultados arrojados mostraron que en un mayor porcentaje las caras grabadas pueden ser contempladas por encima de la barranca y con un valor sensiblemente inferior por debajo de esta. Los porcentajes más bajos se encontraron entre los bloques cuyos grabados pueden ser observados tanto barranca arriba como abajo o desde la planicie, esto es, alejándose más de $30 \mathrm{~m}$ del borde del cauce (Tabla 4; Figura 2). Al igual que ocurrió con las variables anteriores, no se observaron diferencias significativas entre el subconjunto formativo y el tardío $\left(\mathrm{X}^{2}=1,3 ; \mathrm{gl} 2 ; \mathrm{p}=0,7220\right)$.

Del análisis de la matriz de datos se desprendió que la mayoría de los motivos representados en los bloques no pueden ser divisados desde otros (C1), seguidos en orden de representación por aquellos que son vistos desde un único bloque (C2), desde más de dos (C4) o desde dos (C3) (Tabla 5; Figura 3). Tal como ocurre en otras variables, no se observan diferencias significativas entre el subconjunto formativo y tardío en las frecuencias en que cada categoría de visualización está representada $\left(\mathrm{X}^{2}\right.$ $=6,16 ; \mathrm{gl} 3 ; \mathrm{p}=0,1039)$.

Pasando ahora al tamaño de los bloques, los soportes de tamaño grande - entre 0,5 y $1 \mathrm{~m}^{2}$ - son los más representados en el conjunto general; seguidos en orden por los pequeños -entre 0,15 y $0,30 \mathrm{~m}^{2}$-, los medianos - entre 0,30 y $0,50 \mathrm{~m}^{2}$-, los muy grandes - más de $1 \mathrm{~m}^{2}$ - y finalmente, los muy pequeños - menores a $0,15 \mathrm{~m}^{2}$ (Tabla 5; Figura 3). Al tiempo que no existen diferencias significativas para esta variable entre ambos subconjuntos cronológicos $\left(\mathrm{X}^{2}=2,10 ; \mathrm{gl} 4 ; \mathrm{p}=0,7181\right)$.

Finalmente se analizaron dos variables directamente vinculadas a la intensidad de uso del espacio. Una de ellas fue el número de caras grabadas. Como se desprende de la Tabla 6, la mayoría de bloques del conjunto general presenta sólo una de sus caras grabadas, aun los que evidencian reutilización. No existen marcadas diferencia entre los subconjuntos en el número de caras grabadas, tampoco los reutilizados, aunque ningún bloque temprano mostró tres superficies intervenidas (Figura 4).

La otra variable fue el número de motivos por bloque. Se observó al respecto que la mayoría presenta entre dos y diez grabados (Categoría 2), un número importante de 


\begin{tabular}{|l|c|c|c|c|c|c|c|c|c|}
\hline \multicolumn{2}{|c|}{ Distancias } & \multicolumn{4}{c|}{ Distancia bloques $(\mathrm{m})$} & \multicolumn{4}{c|}{ Distancia ríos (m) } \\
\hline Cronología & Bloques N & Media & D.E. & Mínima & Máxima & Media & D.E. & Mínima & Máxima \\
\hline Formativo & 84 & 20,97 & 20,75 & 1,08 & 91,32 & 37,86 & 19,19 & 3,79 & 89,72 \\
Tardío & 116 & 19,33 & 18,15 & 0,21 & 83,97 & 36,56 & 21,39 & 3,77 & 137,37 \\
\hline
\end{tabular}

Tabla 3. Resultados de los análisis de distancia entre bloques y entre bloques y cursos de agua para cada subconjunto temporal.

\begin{tabular}{|c|c|c|c|c|c|c|c|c|c|c|c|c|}
\hline \multirow[b]{2}{*}{ Cronología } & \multicolumn{5}{|c|}{ Orientación } & \multicolumn{3}{|c|}{ Dirección } & \multicolumn{4}{|c|}{ Posición } \\
\hline & Cenit & NE & NO & SE & SO & $\begin{array}{l}\text { Desde } \\
\text { Acay }\end{array}$ & $\begin{array}{l}\text { Hacia } \\
\text { Acay }\end{array}$ & Indis. & B. Ab. & $\begin{array}{l}\text { B. } \mathrm{Ab} / \\
\mathrm{Ar}\end{array}$ & B. Arr. & Plani. \\
\hline Formativo & o & 29 & 10 & 34 & 11 & 6 & 10 & 68 & 30 & 7 & 32 & 15 \\
\hline Tardío & 4 & 41 & 15 & 38 & 18 & 7 & 20 & 89 & 42 & 8 & 51 & 15 \\
\hline Total & 4 & 70 & 25 & 72 & 29 & 13 & 30 & 157 & 72 & 15 & 83 & 30 \\
\hline
\end{tabular}

Tabla 4. Resultados del análisis de las variables orientación, dirección y posición para cada subconjunto temporal. Referencias: B. Ab. Barranca Abajo; B. Ab/Ar.: Barranca Abajo y Barranca Arriba; B. Arr.: Barranca Arriba; Plani.: Planicie.
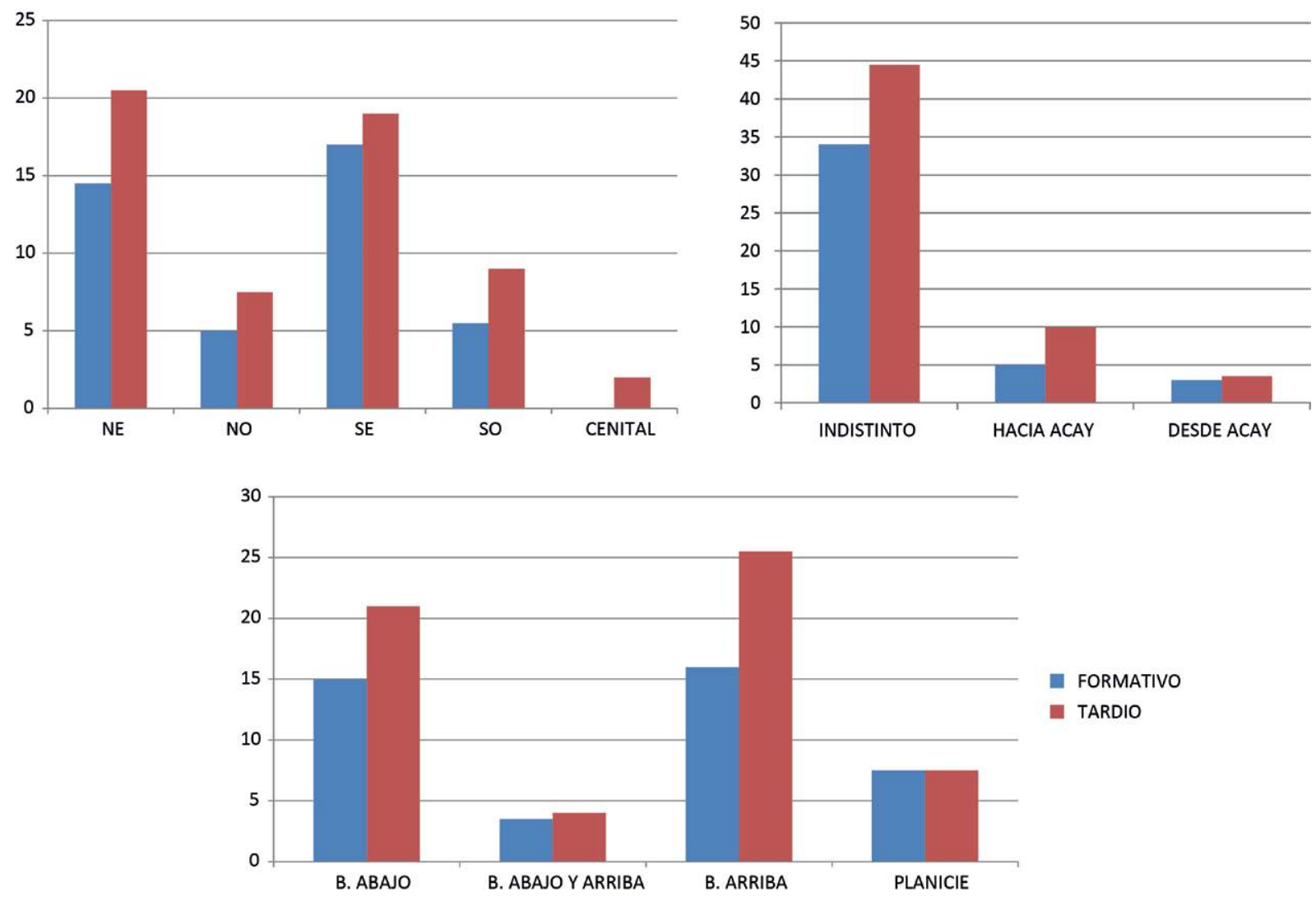

Figura 2. Resultados del análisis de las variables orientación (arriba izquierda), dirección (arriba derecha) y posición (abajo) para cada subconjunto temporal, expresados en porcentajes.

bloques posee sólo un motivo (Categoría 1), siendo escasos los que muestran entre 11 y 20 (Categoría 3) y aún más ocasionales, son los de más de 20 (Categoría 4) (Tabla 6; Figura 4). Y que esta tendencia caracteriza tanto al conjunto de bloques formativos 

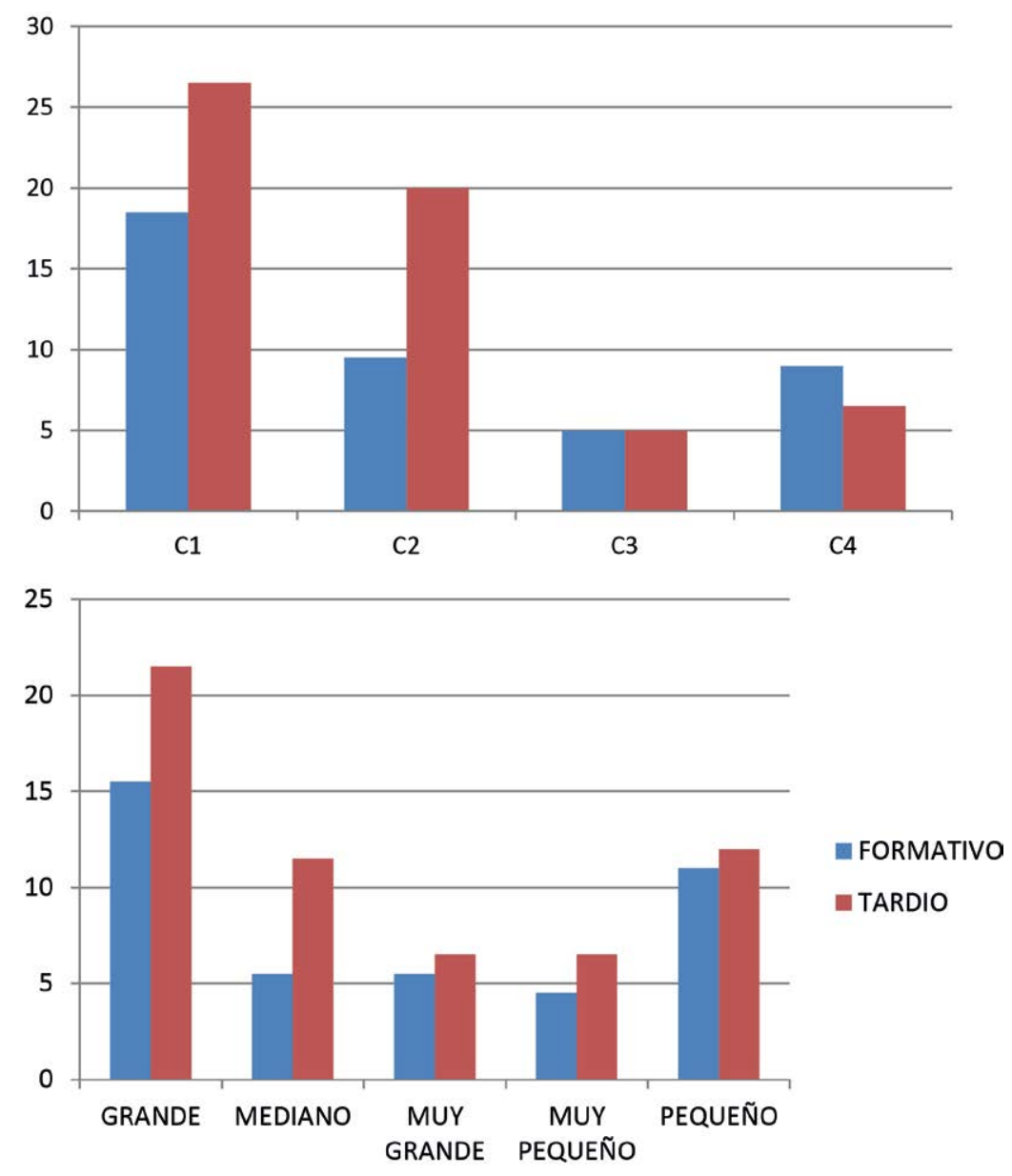

Figura 3. Resultados del análisis de las variables visualización ( $C_{1}$ : bloques no visibles desde otros; $C_{2}$ : vistos desde un bloque; $C_{3}$ : vistos desde tres bloques; $C_{4}$ : vistos desde más de dos bloques) (arriba) y tamaño (abajo) para cada subconjunto temporal, expresados en porcentajes.

\begin{tabular}{|c|c|c|c|c|c|c|c|c|c|}
\hline \multirow{2}{*}{ Cronología } & \multicolumn{4}{|c|}{ Visualización } & \multicolumn{5}{|c|}{ Tamaño } \\
\hline & $\mathrm{C}_{1}$ & $\mathrm{C}_{2}$ & $\mathrm{C}_{3}$ & $\mathrm{C}_{4}$ & Muy pequeño & Pequeño & Mediano & Grande & Muy grande \\
\hline Formativo & 37 & 19 & 10 & 18 & 9 & 22 & 11 & 31 & 11 \\
\hline Tardío & 53 & 40 & 10 & 13 & 13 & 24 & 23 & 43 & 13 \\
\hline Total & 90 & 59 & 20 & 31 & 22 & 46 & 34 & 74 & 24 \\
\hline
\end{tabular}

Tabla 5. Resultados del análisis de las variables visualización y tamaño para cada subconjunto temporal.

como tardíos, así como a aquellos reutilizados, excepto porque no se registran bloques tempranos con más de 20 motivos. Mientras que el número de motivos para esta misma categoría en bloques reutilizados es más del doble $(n=5)$ que lo observado en bloques del periodo Tardío $(\mathrm{n}=2)$.

Del texto se desprende que el número de grabados asignables cronológicamente al período Tardío es superior al del conjunto más temprano. Unos 84 bloques presentan motivos formativos y 116 poseen representaciones que corresponden a los momentos más tardíos de la secuencia. Por otra parte, de este último número 37 bloques muestran 

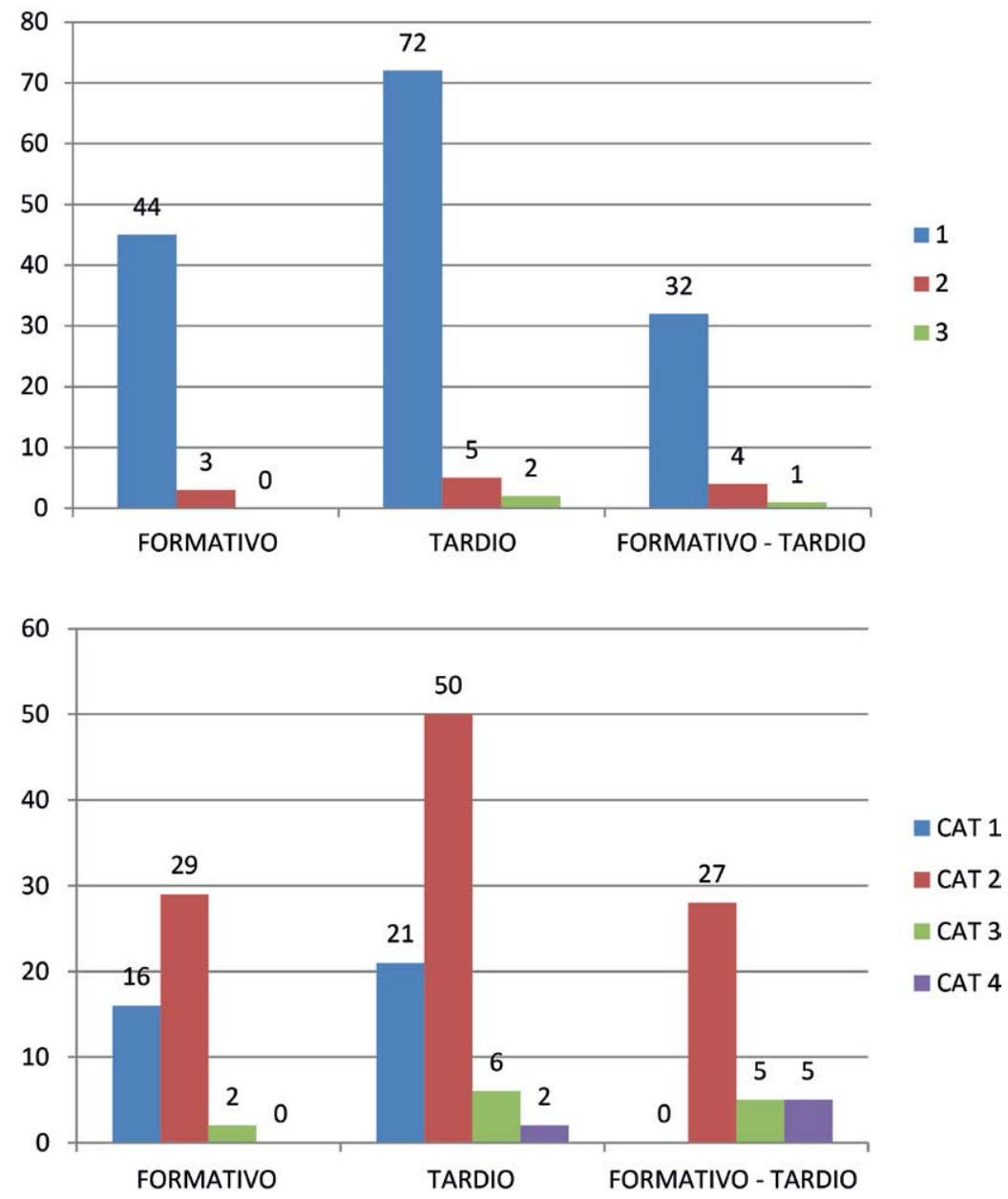

Figura 4. Número de caras grabadas (arriba) y motivos (Categoría 1: un motivo por bloque; Categoría 2: entre dos y diez motivos; Categoría 3: entre 11 y 20 motivos; Categoría 4: más de 20 motivos) (abajo) en bloques formativos, tardíos y reutilizados, expresados en frecuencias.

\begin{tabular}{|l|c|c|c|c|c|c|c|}
\hline \multirow{2}{*}{ Cronología } & \multicolumn{3}{|c|}{ Caras grabadas } & \multicolumn{4}{c|}{ Motivos } \\
\cline { 2 - 8 } & $\mathbf{1}$ & $\mathbf{2}$ & $\mathbf{3}$ & $\mathbf{1}$ & Hasta 10 & Hasta 20 & Más de 20 \\
\hline Formativo & 44 & 3 & 0 & 16 & 29 & 2 & 0 \\
Tardío & 72 & 5 & 2 & 21 & 50 & 6 & 2 \\
Form/Tard. & 32 & 4 & 1 & 0 & 27 & 5 & 5 \\
\hline Total & $\mathbf{1 4 8}$ & $\mathbf{1 2}$ & 3 & 37 & 106 & 13 & 7 \\
\hline
\end{tabular}

Tabla 6. Número de caras grabadas y motivos en bloques formativos, tardíos y reutilizados.

motivos que han sido ejecutados en rocas previamente intervenidas, correspondiendo esto al 33\% de los bloques tardíos. Sobre este conjunto se llevó a cabo el análisis intrabloque, desde el que se abordaron las relaciones espaciales entre motivos de un mismo soporte.

En referencia a esto, se registró que del total de bloques reutilizados una amplia mayoría posee una única cara grabada donde se plasman motivos asignables a ambos momentos, 
Formativo y Tardío (ver Tabla 6). Del análisis de las asociaciones entre motivos y temáticas representadas en dichos casos, se desprenden algunas regularidades:

Camélidos geométricos o rectilíneos de los patrones H2a y H3 tardíos (Aschero, 2000, Figuras $5 \mathrm{E}$ y $10 \mathrm{~A}$ respectivamente) se agregan a otros preexistentes de patrones de diseños más realistas, con cuatro patas y dos orejas, dispuestos en forma aislada o agrupados, ya sea esto en hilera (Figura 5A), o en distinto plano virtual de apoyo o dirección (Figura 5B). Las muescas también son otro motivo que frecuentemente aparece agregado en estos temas durante el Tardío.

Es recurrente el agregado de camélidos de patrones lineales más tardíos en bloques que presentan figuras humanas de cuerpo geométrico elongado, y extremidades $3 / 4$ perfil o mascariformes formativos, ocupando lugares centrales o destacados, yuxtapuestos a motivos tempranos de camélidos o suris (Figura 5D).

En muy pocos casos $(n=2)$ se observa que las nuevas figuras afecten otras previas. La Figura 5C es un claro ejemplo de superposición de motivos.

Otro aspecto significativo es que en estos bloques, y también en otros no reutilizados, no se observan diferencias en las técnicas de grabado aplicadas en cada momento, predominando siempre los picados continuos o discontinuos de cuerpo lleno y el surco picado continuo.

Existen además, motivos tardíos para los cuales siempre se opta por paneles antes no utilizados. Es el caso de las figuras humanas con túnica triangular del patrón G3 (Aschero, 2000, figura 15b) (Figura 5E y 6H) o con atributos como varas, bastones y tocados; las alineaciones de camélidos con pechera del patrón H2a (Aschero, 2000, figura 5D); escenas de tiro de camélidos del patrón H1 (Aschero, 2000, figura 7A y B) (Figura 6E) o en el caso que se muestra como ejemplo, con lazos y tarabitas (Figura $5 \mathrm{~F}$-bloque donde además se han impuesto otros motivos con posterioridad- $\mathrm{y}$ $6 \mathrm{D})$.

\section{Recapitulación de los resultados}

Los análisis realizados abordaron aspectos vinculados con la espacialidad y visibilidad de los conjuntos rupestres. En tal sentido, se evaluó el patrón de distribución de los subconjuntos de bloques asignados a momentos formativos y tardíos. Los bloques, tanto aquellos tempranos como más tardíos, se emplazan en el terreno definiendo un trazado lineal, similar en cuanto a su longitud y direccionalidad. Los resultados de los análisis de distancia entre bloques y de estos últimos respecto de los cursos de agua mostraron que no existen diferencias significativas entre ambos subconjuntos.

Podría sugerirse que estas similitudes resultan de las características de la geomorfología local, principalmente de la topografía, de la disposición de los cursos de agua y las vegas adyacentes, actuando como condicionantes de estas distribuciones. En este sentido, no puede desestimarse que estos factores han sido claves y determinantes en la selección del área y de los bloques a grabar, tratándose de paisajes vinculados al pastoreo de camélidos, pero no explican por sí mismos otras semejanzas observadas entre el subconjunto rupestre formativo y el otro más tardío. Por ejemplo, respecto a la variable distancia entre bloques, sería esperable que la menor densidad que se registra durante momentos tempranos resulte en trayectos más largos entre los soportes elegidos, no obstante esto no ocurre. Es decir, que los nuevos grabados que se agregan en momentos tardíos se distribuyen manteniendo un distanciamiento semejante al del patrón preexistente. 

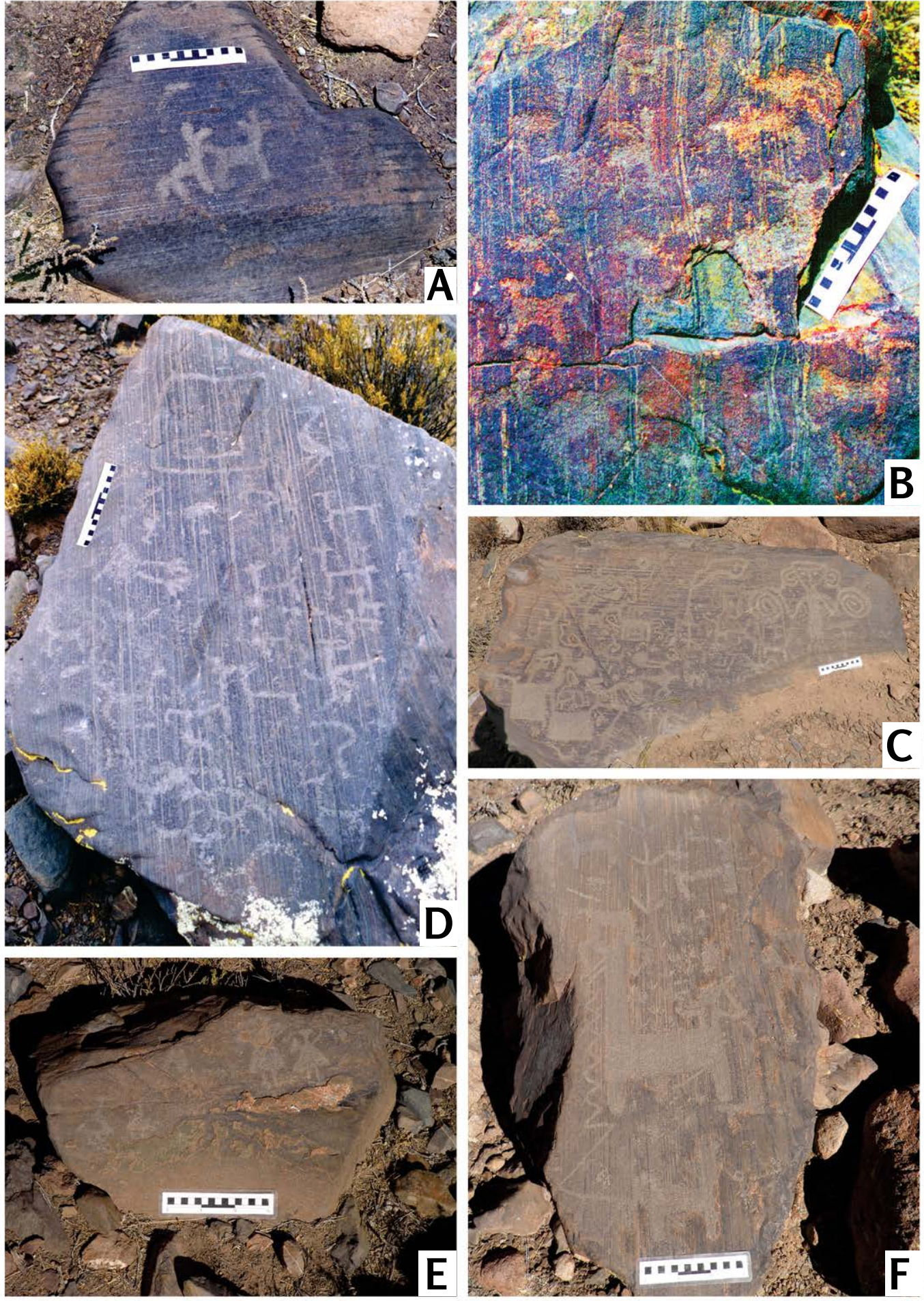

Figura 5. A) Bloque con superposición de camélidos con diferente patrón y pátina en una misma dirección y plano virtual de apoyo; B) Camélidos y aves con diferente patrón en distinta dirección y planos de apoyo (fotografía con retoque digital que permite resaltar diferencias de pátina); C) Bloque con superposición de motivos ;D) Motivo mascariforme yuxtapuesto a motivos de aves y camélidos, los últimos de patrón lineal; E) Figuras antropomorfas de vestimenta triangular, agrupadas; F) Camélidos de contornos geométricos, con lazos y tarabitas. Nota: Escala gráfica $15 \mathrm{~cm}$.

Otras variables analizadas, que condicionan posiciones de observación y también de desplazamiento en el paisaje, muestran una tendencia similar. Se observó un marcado predominio de las caras con orientación sudeste y noreste para todo el conjunto de 
bloques. Se recordará además que la gran mayoría tiene una única cara grabada, lo cual restringe las posiciones desde donde se pueden aprehender los motivos. Esta orientación delimita un espacio de visualización para las representaciones mayormente ubicado al este de los conjuntos, entre el curso de agua y la línea virtual que define la alineación de bloques rupestres. Por su parte, el análisis de la variable referida a la posición de observación reflejó que la mayoría de los bloques pueden ser vistos desde arriba de la barranca, un número similar desde abajo y en menos casos desde la planicie, o tanto desde arriba como desde abajo del perfil del cauce. En síntesis, esta línea de observación y circulación que mencionamos antes, se ubicaría hacia el este de los grabados, en ocasiones por encima y en otras por debajo del borde de la barranca del río. Por último, no se observó que los bloques definan sentidos de desplazamiento en el terreno, ya que la amplia mayoría pueden ser vistos siguiendo esta alineación en una o en otra dirección. Dichas tendencias se observan para el conjunto formativo y se mantienen en momentos tardíos, lo cual daría cuenta de la continuidad de este patrón de organización espacial a lo largo del tiempo. Esto incluso se reproduce actualmente, ya que esta misma ruta es la que hoy utilizan los pastores locales para desplazar el ganado caprino y ovino desde el fondo de la cuenca hasta los puestos de invernada.

Variables tales como la visibilidad de los bloques o su tamaño tampoco mostraron cambios en el tiempo. Del análisis de esta última se desprendió que se ha optado

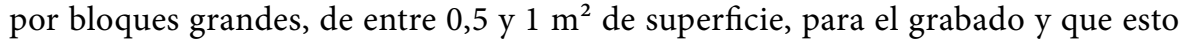
se observa en ambos subconjuntos temporales. Estos bloques seleccionados se hallan dispersos naturalmente en el área y no se destacan por su tamaño de otros no grabados. Por otro lado, no existen restricciones para su acceso ni físico ni visual, no obstante, los bloques no presentan una alta visualización. Sólo un 16\% de los bloques del conjunto general poseen motivos que pueden ser vistos desde más de tres posiciones. Alrededor del $40 \%$ de los mismos son observables desde uno o dos bloques, y según se ha constatado en el terreno así como en la cartografía generada en la plataforma SIG, son los más cercanos a ellos. Esta condición determina que el observador, también circulante, divise desde un bloque el grabado más próximo, o varios de ellos, pautando de esta forma un determinado modo de circulación en ese espacio. Para otro porcentaje, que ronda el $45 \%$ del total de la muestra, se divisa el bloque, no así el motivo grabado, que es percibido sólo al aproximarse al soporte. Por este motivo consideramos que la localización en el terreno estaría sujeta al conocimiento del paisaje por parte de los individuos o grupos de pastores, que surge de una práctica reiterada a través del tiempo, especialmente teniendo presente que un número importante de los bloques (de alrededor del $34 \%$ del conjunto general) son de tamaño pequeño y muy pequeño.

Más allá de estas continuidades - que también se registran en las técnicas de manufactura- durante el Tardío se habría detectado una mayor intensidad en el uso del espacio, la cual se desprende de la presencia de bloques con tres caras grabadas o con más de 20 motivos, sumado al número superior de bloques grabados asignables a este período, más aun teniendo en cuenta su menor extensión temporal respecto del formativo. Sin embargo, estos bloques más intervenidos no se destacan por la complejidad de sus motivos - círculos, muescas, líneas onduladas- o por ocupar posiciones destacadas en el paisaje como puntos salientes de la topografía, inicio o final de tramos, quiebres del trayecto o bifurcaciones.

De la manera en que han sido reutilizados los bloques también se derivan algunas regularidades. Como se mencionó antes, un 33\% de los bloques asignables al período Tardío presentan grabados previos, y si bien este porcentaje no es despreciable, se observa una preferencia por la utilización de bloques libres, particularmente para ciertos motivos como son la figura humana con vestimenta triangular y/o con tocados $y$ objetos, o los agrupamientos o alineaciones de camélidos rectilíneos, con o sin pechera. 
En los casos que se ha optado por utilizar bloques previamente intervenidos, los motivos que se plasman no suelen afectar los diseños ya existentes, siendo escasas las figuras impuestas sobre otras previas, los picados y demás formas de obliteración. Por el contrario, se observa que muchos de los motivos tardíos de estos bloques reutilizados se agregan a los paneles manteniendo las temáticas o las distribuciones ya existentes. Tal es el caso de las alineaciones de camélidos o los camélidos y suris en torno a figuras antropomorfas o mascariformes tempranas. Parecería entonces, que estos motivos preexistentes continúan siendo relevantes en esos nuevos discursos, aun cuando su significado no necesariamente debió ser el mismo.

Resumidamente, el análisis de los aspectos distribucionales y visuales de los bloques del Tramo 1 de La Damiana no sugiere cambios significativos entre los períodos estudiados, aunque sí una mayor intensidad en el uso del espacio. Asimismo, se desprende de los resultados que los bloques preexistentes no son excluidos de las configuraciones más tardías, integrándose en ellas no sólo desde su disposición, sino también desde la movilidad y la visibilidad. En tal sentido, no se observa una negación de los motivos o temáticas previamente plasmadas, aun cuando el repertorio iconográfico del Tardío incluye nuevos temas y cánones y patrones diferentes de representación (Aschero, 2000; Martel, 2011; Martel y Aschero, 2007).

\section{Valoración de los resultados}

En esta sección se exploran de manera preliminar algunas propuestas respecto de las prácticas vinculadas al manejo de camélidos en sociedades prehispánicas, materializadas en parte en el arte rupestre, sus temáticas y arreglos espaciales, y de sus cambios a través del tiempo.

Según la información presentada para La Damiana, al igual que ocurre con otros sitios con arte rupestre de Quebrada del Toro (De Feo, 2014a, 2015; De Feo y Ferrauiolo, 2007; Meninato, 2008), los bloques con grabados no sólo indican, ya sea el inicio de áreas productivas o los caminos que conducen hacia ellas, sino que también pautan el movimiento en el espacio, condicionando la forma en que debe ser percibido ese entorno; definiendo senderos, líneas de circulación, direcciones y posiciones desde las cuales los motivos pueden ser contemplados. Y estas formas de ordenar el espacio, según la evidencia presentada, poseen una larga persistencia en el tiempo.

Como se ha mencionado brevemente en la introducción de este trabajo, cambios importantes en los sistemas socio-políticos y económicos ocurrieron en las comunidades aldeanas locales hacia principios del segundo milenio de la era, aunque algunos indicios de este proceso se remontan unos cinco siglos atrás (De Feo, 2014b). Formas de organización basadas en la familia dan paso a otras más complejas, caracterizadas por el surgimiento de élites y jefes regionales. Las pequeñas aldeas, espacios de residencia y producción agrícola, son abandonadas, y la población se concentra en grandes centros urbanos como Santa Rosa de Tastil, Morohuasi o Puerta de Tastil, proceso que además implicó un marcado crecimiento de la densidad demográfica (Cigliano y Raffino, 1973; Raffino, 1972). Si bien actividades tales como el pastoreo o la caza se hallan documentadas al igual que la explotación estacional u ocasional de espacios con oferta diferencial de recursos, durante el Tardío se registra una intensificación de la agricultura, evidenciada por el desarrollo de tecnologías para el riego y la modificación de la pendiente, así como también el surgimiento de sitios especializados en la producción agrícola, como son Pie de Chañi, Pie de Paño y Pie del Acay (Raffino, 1972), este último ubicado también en Incahuasi. Asimismo, para este período se menciona un fortalecimiento del control de las élites en los circuitos de intercambio macro-regionales y el tráfico caravanero (Aschero, 2000; Nielsen, 1997-1998), que 
ya se encontraban vigentes al menos desde el Formativo (Álvarez Soncini y De Feo, 2010; De Feo, 2015; De Feo y Álvarez Soncini, 2010; Pereyra Domingorena, De Feo y Bugliani, 2015; Raffino, 1977).

Pese a estas transformaciones, la continuidad en el patrón de organización espacial del arte rupestre así como la incorporación de soportes o motivos tempranos dentro de las lógicas de ordenamiento tardías - aun cuando pudieran ser re-significados-, nos hablan de la persistencia de ciertos aspectos en la práctica del pastoreo de camélidos y del caravaneo desde el período Formativo al Tardío, y de cómo estas actividades se desarrollaron en el paisaje y de la red de relaciones sociales que involucraron. Sobre esta última actividad, se dijo en un inicio que la iconografía registrada en La Damiana respondería a contextos pastoriles más que caravaneros. Dentro del conjunto documentado están presentes alineaciones de camélidos, representados con indicación de carga o tarabitas o unidos por sogas - pudiendo o no estar precedidos y/o tirados por figuras humanas - así como ciertos diseños abstractos que se han vinculado al tráfico caravanero del Centro-Sur Andino (Aschero, 2000; Berenguer, 2004; Muñoz y Briones, 1998; Núñez, 1985; Núñez y Dillehay, 1995; Yacobaccio, 1979) aunque en bajo número. No obstante, espacialmente esta iconografía no se separa o destaca de otros bloques, coexistiendo en un mismo sendero. La evidencia no parece indicar que el pastoreo y el caravaneo fueran actividades separadas en el paisaje, al menos en el tramo analizado. Sobre esto último, algunos ejemplos citados en la bibliografía etnográfica, etnohistórica y arqueológica, cuestionan que tal segregación de espacios ocurra de manera excluyente, señalando casos frecuentes donde ambas prácticas se superponen espacialmente; dando cuenta además, que son los mismos actores sociales quienes pueden llevar a cabo estas actividades y, consecuentemente, quienes son los responsables de la producción y significación del arte rupestre pastoril/caravanero (Martel, 2009; Nielsen, 1997-1998, 2006)

Volviendo a las transformaciones documentadas para momentos tardíos, se ha sugerido que los cambios en la organización socio-política y en la economía habrían afectado en mayor medida a los referentes objetivos del arte rupestre y cómo estos son representados, más que el marco económico en el que es producido o a quienes y dónde lo hacen (Aschero, 1996-1998, 2000; Martel y Aschero, 2007). Con relación a esto último, los análisis presentados indican que no ocurren grandes cambios en la manera en que se configura el paisaje durante este período respecto de lo previamente documentado, aunque si se observa una mayor intensidad en el uso del espacio. Esto ha sido verificado para el Tramo I de La Damiana, sin embargo, debemos ser cautelosos en generalizar esta situación a toda la localidad. El número de bloques registrados a la fecha es significativamente superior al estudiado, y estos también conforman trayectos o recorridos, se asocian a cursos de agua y pasturas, pero además a sectores de residencia o de producción agrícola. Su estudio se encuentra actualmente en proceso y puede arrojar nueva información sobre la distribución del arte rupestre en el paisaje en una escala más amplia y su asociación con otro tipo de evidencias.

Por otra parte, Martel y Aschero (2007) mencionan varios escenarios posibles sobre cómo estas transformaciones ocurridas durante el Tardío en el orden socio-político y económico se vieron reflejadas en los conjuntos rupestres, las temáticas e íconos seleccionados para su representación y en sus interacciones con diseños previos. Algunas de ellas graficarían las situaciones observadas en el Tramo 1 de La Damiana. Por ejemplo, ocasiones en que camélidos de diseños rectilíneos tardíos, son agregados junto a íconos formativos como son los "hombre cigarro" o los mascariformes. Otra situación es la segregación espacial de motivos que aluden al poder de jefes o élites respecto de otros menos conflictivos como son los camélidos o los antropomorfos no jerarquizados. Figuras humanas con uncus y/o tocados portando objetos como bastones, varas u otros, los escutiformes, los ancariformes y las hachas o cuchillos más 
3. A la fecha sólo se han documentado tres escenas como las mencionadas. Se ubican en bloques cercanos entre sí, dispuestos en el extremo noroeste del cono de deyección, uno de ellos del mismo lado que La Damiana y los dos restantes cruzando la Ruta Nacional 51, próximos a un cauce de agua permanente conocido como "el grande" y en el inicio de una extensa vega de fondo de valle y de un sector de viviendas. Por su parte, en el tramo analizado, los motivos antropomorfos del patrón

$\mathrm{G}$ se presentan o bien aislados o de a pares, donde sí en este último caso, uno porta objetos y puede ser de un tamaño levemente mayor. o menos antropomorfizados del Tardío son considerados como la representación de estos procesos de surgimiento y consolidación del poder de las élites o curacas (Aschero, 2000; Berenguer, 2004; Martel, 2009; Montt y Pimentel, 2006; Podestá et al., 2013). En el caso analizado se observan nuevos cánones y patrones de representación para camélidos y antropomorfos. Para ambos tipos de motivos se ha observado que algunas modalidades tienden a representarse en paneles libres, aunque siempre manteniendo patrones espaciales y visuales preexistentes; nos referimos a los camélidos con pechera en hilera o de tratamiento geométrico rectilíneo, las escenas de tiro de esta última variante de camélidos o las figuras humanas con vestimenta triangular, aisladas, que en escasas ocasiones portan varas o algún otro tipo de instrumento (Figuras 5E y F y 6B, D, E y H). Muy poco frecuentes son, asimismo, los escutiformes (un caso observado del patrón H4 sensu Aschero, 2000, figura 19) o los tupus. Escenas donde las figuras humanas del patrón G3 se representan organizadas en hileras, precedidas por otras más ataviadas con tocados complejos o vestimentas diferenciales como uncus y/o portando objetos, son aún menos recurrentes en Incahuasi $^{3}$ y no están presentes en el Tramo 1 aquí estudiado.

Sobre estas escenas, el reemplazo de figuras antropomorfas tardías, simples y aisladas, como las que se registran mayormente en La Damiana, por otras donde existe un mayor despliegue de atributos indicadores de diferenciación social, emblemas corporativos u otros íconos de autoridad, ha sido leído como un posible indicador de la consolidación de poder de las elites durante el Tardío (Adris, 2009-2011; Nielsen, 2007). No obstante y como señalan estos autores, estos procesos no necesariamente debieron implicar un control estricto sobre la producción local y el tráfico regional. En esta dirección podría interpretarse la evidencia analizada, en la que las figuras ataviadas, portando bastones o instrumentos, precediendo otras menos jerarquizadas, o los grandes escutiformes, son poco frecuentes. Pensamos que este poder sí se habría manifestado con mayor presencia e intensidad en las cercanías de sitios de residencia, particularmente de Santa Rosa de Tastil, el más grande núcleo urbano de la Quebrada del Toro. Próximos a este último asentamiento, en Abra de Romero, danzantes, uncus y escutiformes aparecen representados con más frecuencia en sitios con arte rupestre como Corral Negro, El Duraznito, Cerro Abra Romero y El Negro (Meninato, 2008).

La ausencia de estos íconos en el tramo analizado podría estar indicando cierta autonomía de acción de los individuos o grupos de pastores/caravaneros, productores del arte rupestre, respecto de estas emergentes estructuras de poder. La coexistencia de estrategias de comunicación que antes se mencionaron, esto es, el surgimiento de nuevos íconos o temas que se imponen y participan de estos renovados discursos visuales, a la vez que coexisten con otros previos, creemos podría ser reflejo de esta situación. Sobre los motivos mascariformes o antropomorfos geometrizados tempranos, Aschero y Korstanje (1996) proponen que estas figuras podrían representar la materialización del ancestro, destacando su rol como demarcadores de la posesión de territorios por parte de una determinada comunidad o linaje, a la vez que los vinculan con prácticas relacionadas con la fertilidad de las pasturas y la reproducción de los animales. El hecho de que bloques con tales íconos no sean excluidos de los recorridos, y sean incluso reutilizados, podría sugerir cierta vigencia en las prácticas y ritos locales vinculados al pastoreo/caravaneo de camélidos o, como sugiere Aschero (2000), que su beneficio hacia las tropas de camélidos era conocida o resignificada, si bien evidentemente dejan de ser replicados.

Todo lo anterior no implica desconocer los cambios documentados en el orden sociopolítico y económico de estas sociedades durante el Tardío en los conjuntos rupestres, manifestados principalmente por la ocurrencia de nuevos temas y formas de representación - aspecto que estaría reflejando cambios en los "contextos de significación" de estos grupos como se ha sugerido para otros sectores del área circumpuneña (Aschero, 2000, p. 17) - sino relativizar sus consecuencias en la 

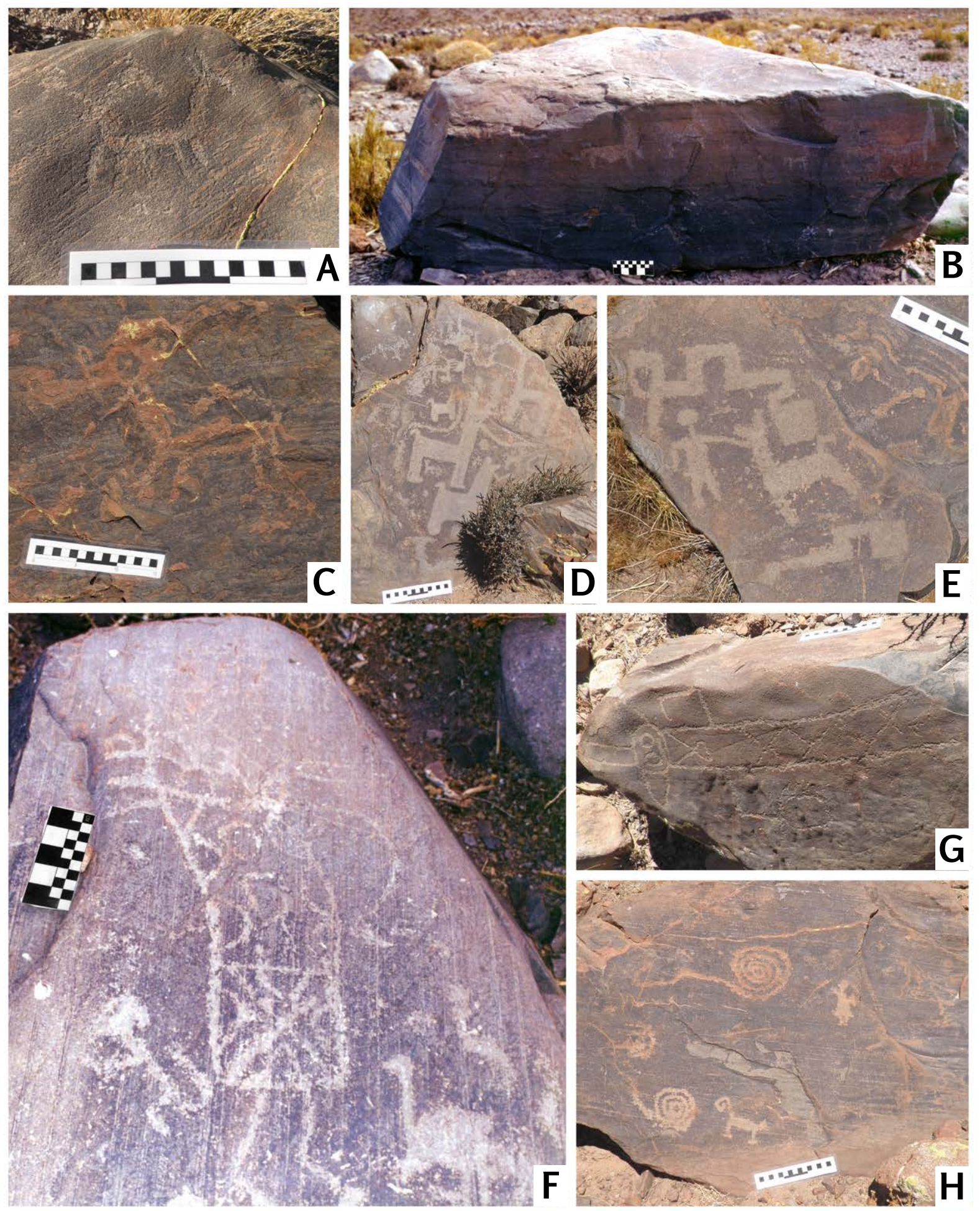

Figura 6. A y C) Motivos de camélidos formativos: camélido con 4 patas y dos orejas y camélido con atributos felínicos; B y D) Motivos de camélidos tardíos: camélidos con pechera alineados y camélidos de patrón rectilíneo con sogas; E) Camélidos de patrón rectilíneo tardíos, tirados por figura humana; F y G) Antropomorfos formativos de cuerpos geometrizados elongados; H) Antropomorfo con uncu tardío. Nota: Escala gráfica $15 \mathrm{~cm}$.

organización de las prácticas ligadas al manejo del ganado, sobre la red de relaciones sociales que se establecen, las personas que lo llevan a cabo y los rituales a ellas asociadas. 
La evidencia presentada para el Tramo 1 de La Damiana muestra cambios y continuidades para el período Tardío respecto de momentos previos. Continuidad en la manera en que el espacio es organizado y utilizado en el marco de las actividades pastoriles/caravaneras, en la recurrencia de ciertos temas como son los camélidos y los antropomorfos y en la reutilización y/o resignificación de motivos preexistentes. A su vez, nuevos temas e íconos se imponen. Comprender estos procesos en toda su complejidad requiere profundizar varias líneas de investigación. Por un lado, ampliar el relevamiento de sitios con arte rupestre asignables cronológicamente a distintos momentos de la ocupación prehispánica, y por otro, establecer tendencias en la distribución de ciertos motivos o temáticas y su asociación particular con diferentes tipos de sitios (poblados, sitios de producción agrícola yo pastoril, rutas o senderos, entre otros). En estas direcciones se está trabajando actualmente.

\section{Agradecimientos}

A Lucia Coria y familia, a la comunidad de Las Cuevas y al Sr. Gerón por apoyar nuestras investigaciones en el área. Por el mismo motivo a la familia Taritolai, especialmente a Mirta e Hipólito y al Sr. José. A Pedro Cruz. A María Alejandra Bazzano por las horas bajo el sol, con calor o frío, con viento o con agua nieve, documentando grabados en el campo; sin su ayuda esta tarea no hubiese sido posible. A Diego Gobbo por el diseño de las figuras que acompañan el texto. A Iván Pérez y Reinaldo Moralejo por responder mis consultas sobre estadística. A Enrique Moreno por emprender la organización del simposio que dio el puntapié para esta publicación. A María José Figuerero y Guillermo Mengoni por su generosidad. Finalmente, a los evaluadores por sus valiosos aportes a la versión original del manuscrito. Estas investigaciones fueron financiadas parcialmente con un subsidio UNLP (N806). 


\section{Referencias citadas}

"Adris, S. (2009-2011). Al filo de la aguada: aportes al estudio del arte rupestre de Cerro Negro, sector Septentrional de la Quebradade Humahuaca (Jujuy, Argentina). Mundo de antes, 6-7, 133-162.

" ÁlvarezSoncini,M.C.yDeFeo,M.E.(2010). Obsidianas en contextos tempranos dela Quebrada del Toro: Análisis tecno-morfológico e identificación de fuentes de aprovisionamiento en los sitios Las Cuevas I y V. En J. Bárcena y H. Chiazazza (Eds.), Actas del XVII Congreso Nacional de Arqueología Argentina (Tomo I) (pp. 19-24). Mendoza: Universidad Nacional de Cuyo.

" Armstrong, F. (2012). Engraved memory: petroglyphs and collective memory at Los Mellizos, Illapel, Chile. Rock Art Research, 29(1), 19-34.

"Aschero, C. (1996-1998). Arte y arqueología: una visión desde la Puna argentina. Chungara. Revista de Antropología Chilena, 28(1 y 2), 175- 197.

"Aschero, C. (2000). Figuras humanas, camélidos yespacios de interacción circumpuneña. En M. M. Podestá y M. de Hoyos (Eds.), Arte en las Rocas. Arte Rupestre, menhires y piedras de colores en Argentina (pp. 15- 44). Buenos Aires: Sociedad Argentina de Antropología.

》 Aschero, C. y Korstanje M. A. (1996). Sobre figuraciones humanas, producción y símbolos. Aspectos de arte rupestre del noroeste argentino. En M. C. Rivolta (Ed.), Volumen del XXV Aniversario del Museo Arqueológico Dr. Eduardo Casanova (pp. 13-31). Tilcara: Instituto Interdisciplinario Tilcara (UBA).

》 Aschero, C., Podestá, M. M. y García, L. (1991). Pinturas Rupestres y asentamientos cerámicos tempranos en la Puna Argentina. Arqueología, 1, 9-49.

» Berenguer, J. (2004). Caravanas, Interacción y Cambio en el Desierto de Atacama. Santiago: Sirawi Ediciones.

"Boman, E. (1908). Antiquités de la Región Andine de la Republique Argentine et du Désertd' Atacama. París: Mission Scientifique G. de Créqui Montfort et E. Sénéchal de la Grange. Imprimiere Nationale, Volumen II.

» Cigliano, E. y Raffino, R. (1973). Tastil, un modelo cultural de adaptación, funcionamiento y desarrollo de una sociedad urbana prehistórica. Relaciones de la Sociedad Argentina de Antropología, VII, 159-181.

"Criado, F. (1993). Visibilidad e interpretación del registro arqueológico. Trabajos de Prehistoria, 50, 39-56.

"De Feo, M. E. (2013). Grabados en la memoria: Arte rupestre y paisajes pastoriles en la Quebrada del Toro, Salta. Trabajo presentado en el XVIII Congreso Nacional de Arqueología Argentina, La Rioja, Argentina.

»De Feo, M. E. (2014a). El arte rupestre de la Quebrada de Incahuasi, Salta, Argentina: Materialidad, tiempo y espacio en La Damiana I, II y III. Trabajo presentado en el Primer Congreso Nacional de Arte Rupestre, Rosario, Argentina.

»De Feo, M. E. (2014b). Paisajes aldeanos de la Qda. del Toro, Salta, durante el Período Formativo tardío (s. V al IX d.C.). Revista Escuela de Historia, 13(2), 0-29.

» De Feo, M. E. (2015). Puesta al día sobre el Formativo de la Quebrada del Toro (Salta, Argentina). En M. A Korstanje, M. Lazzari, M. Basile, M. F. Bugliani, V. Lema, L. Pereyra Domingorena y M. Quesada (Eds.), Crónicas materiales precolombinas. Arqueología de los primeros poblados del Noroeste Argentino (pp. 277-311). Buenos Aires: Sociedad Argentina de Antropología. 
»De Feo, M. E. (2017). Informe Anual. Informe al CONICET. Manuscrito inédito.

»De Feo, M. E. y Álvarez Soncini, M. C. (2010). Estudio tecnomorfológico y análisis de procedencia de obsidianas recuperadas en el sitio formativo Tres Cruces I (Quebrada del Toro, Pcia. de Salta, Argentina). En S. Bertolino, R. Cattáneo y A. Izetta (Eds.), La arqueometría en Argentina y Latinoamérica (pp. 165-170). Río Cuarto: Facultad de Filosofía y Humanidades.

»De Feo, M. E. y Ferrauiolo, L. (2007). Grabados Rupestres en el Borde de Puna: sitio La Damiana (Quebrada de Incahuasi, Salta). La Zaranda de Ideas, 3, 41-56.

» Fadel, J. (1977). Mi amiga la montaña. Salta: Fundación Michel Torino.

»Fernández, J. (1988-1989). Ocupaciones alfareras (2860 \pm 160 años A.P.) en la Cueva de Cristóbal, Puna de Jujuy, Argentina. Relaciones de la Sociedad Argentina de Antropología, XVII(2), 139-178.

»Fernández Distel, A. (1998). Arqueología del Formativo en la Puna Jujeña, 1800 ac. 650 dc. Buenos Aires: Maneken.

» Gregory, D. (1978). Ideology, science and human geography. Londres: Hutchinson.

"Lanza, M. (1996). Grabados Rupestres en el Valle Calchaquí: avances y perspectivas. Chungara. Revista de Antropología Chilena, 28, 223-239.

» Martel, A. (2009). Arte rupestre: construcción y significación del espacio en la Puna meridional argentina (Antofagasta de la Sierra, Catamarca). En M. Sepúlveda, J. Chacama y L. Briones (Eds.), Crónicas sobre la piedra. Arte Rupestre de Las Américas (pp. 271-280). Arica: Universidad de Tarapacá.

" Martel, A. (2011). Arte rupestre de pastores y caravaneros. Estudio contextual de las representaciones rupestres durante el Período Agroalfarero Tardío (90o d.c. - 1480 d.c.) en el Noroeste argentino. (Tesis Doctoral inédita), Universidad de Buenos Aires, Argentina.

» Martel, A. y Aschero, C. (2007). Pastores en Acción: Imposición iconográfica vs. autonomía temática. En A. Nielsen, M. C. Rivolta, V. Seldes, M. Vázquez y P. Mercolli (Eds.), Producción y circulación prehispánicas de bienes en el sur andino (pp. 329-349). Córdoba: Brujas.

» Martel, A., Rodríguez Curletto, S. y Del Bel, E. (2012). Arte Rupestre y Espacios de Memoria: Las Representaciones del Sitio Confluencia (Antofagasta de la Sierra, Catamarca, Argentina). Revista Chilena de Antropología, 25(1er Semestre), 121-162.

» Meninato, I. (2008). El arte rupestre de Tastil. Estudio reinterpretativo. (Tesis de Licenciatura inédita), Universidad de Salta, Argentina.

» Montt, I. y Pimentel, G. (2006). Túnicas, petos y “ecutiformes": vestimenta rupestre tardía en la vertiente occidental de la subárea circumpuneña. Trabajo presentado en el VII Simposio Internacional de Arte Rupestre, Arica, Chile.

» Muñoz, l. y Briones, L. (1996). Poblados, rutas y arte rupestre precolombinos de Arica: descripción y análisis de sistema de organización. Chungara. Revista de Antropología Chilena, 28(1-2), 47-84.

» Muscio, H. (2006). Aproximación evolutiva a la complejidad y el orden social temprano a través del estudio de representaciones rupestres de la quebrada de matancillas (Puna argentina). Estudios Atacameños, 31, 9-30.

» Nielsen, A. (1997-1998) Tráfico de caravanas en el Sur de Bolivia: Observaciones etnográficas e implicancias arqueológicas. Relaciones de la Sociedad Argentina de Antropología, XXII-XXIII, 139-178. 
» Nielsen, A. (2006). Estudios internodales e interacción interregional en los Andes circumpuneños: teoría, método y ejemplos de aplicación. En H. Lechtman (Ed.), Esferas de interacción prehistóricas y fronteras nacionales modernas: los Andes sur centrales (pp. 29-69). Lima: IEP-IAR.

» Nielsen, A. (2007). Bajo el hechizo de los emblemas: políticas corporativas y tráfico interregional en los Andes circumpuneños. En A. Nielsen, M. C. Rivolta, V. Seldes, M. Vázquez y P. Mercolli (Eds.), Producción y circulación prehispánicas de bienes en el sur andino (pp. 393-411). Córdoba: Brujas.

» Núnez, L. (1985). Petroglifos y tráfico en el desierto chileno. En C. Aldunate, J. Berenguer y V. Castro (Eds.), Estudios de Arte Rupestre (pp. 243-264). Santiago de Chile: Museo Chileno de Arte Precolombino.

» Núñez, L. y Dillehay, T. S. (1995). Movilidad giratoria, armonía social y desarrollo en los Andes Meridionales: Patrones de tráfico e interacción económica. Antofagasta: Universidad Católica del Norte.

» Olivera, D. y Podestá, M. M. (1993). Los recursos del arte: Arte rupestre y sistemas de asentamiento- subsistencia formativos en la Puna meridional argentina. Arqueología, 3 , 93-141.

»Podestá, M. M. (1986-1987). Arte rupestre en asentamientos cazadores-recolectores y agroalfareros en la Puna sur argentina: Antofagasta de la Sierra, Catamarca. Relaciones de la Sociedad Argentina de Antropología, XVII(1), 241-263.

»Podestá, M. M., Rolandi, D., Santoni, M., Re, A., Falchi, M. P., Torres, M. y Romero, G. (2013). Poder y prestigio en los Andes Centro-Sur. Una visión a través de las pinturas de escutiformes en Guachipas (Noroeste argentino). Boletín del Museo chileno de arte precolombino, 18(2), 63-88.

»Pereyra Domingorena, L., De Feo, M. E. y Bugliani, M. F. (2015). La variabilidad de un estilo: avances y discusiones en torno a la cerámica Vaquerías del Noroeste argentino. En M. A. Korstanje, M. Lazzari, M. Basile, M. F. Bugliani, V. Lema, L. Pereyra Domingorena y M. Quesada (Eds.), Crónicas materiales precolombinas. Arqueología de los primeros poblados del Noroeste Argentino (pp. 449-573). Buenos Aires: Sociedad Argentina de Antropología.

»Raffino, R. (1967). Los Petroglifos del Abra de Romero, Santa Rosa de Tastil. Anales de arqueología y Etnología, XXII, 53-76.

» Raffino, R. (1972). Las Sociedades Agrícolas del Período Tardío en la Quebrada del Toro y aledaños (Pcia. de Salta. Argentina). Revista del Museo de La Plata. Nueva serie, 45, 157-221.

»Raffino, R. (1977). Las aldeas del Formativo inferior en la Quebrada del Toro, (Pcia. de Salta. Argentina). Obra del Centenario del Museo de La Plata, II, 253-299.

» Raffino, R., Tonni, E. y Cione, A. (1977). Recursos alimentarios y economía en la Región de la Quebrada del Toro, Provincia de Salta, Argentina. Relaciones de la Sociedad Argentina de Antropología, XI, 9-30.

»Soria, S. (2007). Sistema de asentamiento en la sierra del Chañi durante el periodo de Desarrollos Regionales (Salta). Cuadernos de la Facultad de Humanidades y Ciencias Sociales, 32, 269-285.

» Troncoso, A. (2005). Un espacio, tres paisajes, tres sentidos: la configuración rupestre en Chile central. TAPA, 33, 69-81.

»Troncoso, A. (2007). Arte Rupestre y microespacios en el Valle de Putaendo, Chile: entre movilidad, la visibilidad y el sentido. En A. Nielsen, C. Rivolta, V. Seldes, A. M. Vázquez y P. Mercolli (Eds.), Procesos sociales prehispánicos en el Sur Andino. La vivienda, la comunidad y el territorio (pp. 393-411). Córdoba: Brujas. 
» Yacobaccio, H. (1979). Arte Rupestre y tráfico de caravanas en la Puna de Jujuy: modelo e hipótesis. En Actas de las Jornadas de Arqueología del Noroeste argentino (pp. 392 - 401). Buenos Aires: Universidad del Salvador. 